\title{
The impact of universal National Health Insurance on population health: the experience of Taiwan
}

\author{
Yue-Chune Lee ${ }^{1}$, Yu-Tung Huang ${ }^{2}$, Yi-Wen Tsai ${ }^{3}$, Shiuh-Ming Huang ${ }^{4}$, Ken N Kuo ${ }^{3}$, Martin McKee ${ }^{5}$, Ellen Nolte ${ }^{6}$
}

\begin{abstract}
Background: Taiwan established a system of universal National Health Insurance (NHI) in March, 1995. Today, the $\mathrm{NHI}$ covers more than $98 \%$ of Taiwan's population and enrollees enjoy almost free access to healthcare with small co-payment by most clinics and hospitals. Yet while this expansion of coverage will almost inevitably have improved access to health care, however, it cannot be assumed that it will necessarily have improved the health of the population. The aim of this study was to determine whether the introduction of National Health Insurance $(\mathrm{NHI})$ in Taiwan in 1995 was associated with a change in deaths from causes amenable to health care.

Methods: Identification of discontinuities in trends in mortality considered amenable to health care and all other conditions (non-amenable mortality) using joinpoint regression analysis from 1981 to 2005.

Results: Deaths from amenable causes declined between 1981 and 1993 but slowed between 1993 and 1996. Once NHI was implemented, the decline accelerated significantly, falling at 5.83\% per year between 1996 and 1999. In contrast, there was little change in non-amenable causes (0.64\% per year between 1981 and 1999). The effect of $\mathrm{NHI}$ was highest among the young and old, and lowest among those of working age, consistent with changes in the pattern of coverage. NHI was associated with substantial reductions in deaths from circulatory disorders and, for men, infections, whilst an earlier upward trend in female cancer deaths was reversed.
\end{abstract}

Conclusions: NHI was associated in a reduction in deaths considered amenable to health care; particularly among those age groups least likely to have been insured previously.

\section{Background}

Taiwan established a system of universal National Health Insurance (NHI) in March, 1995, replacing 13 occupational funds that had covered only about $60 \%$ of the population (including military health services), largely covering the population at working age. Coverage was $14 \%, 77 \%$, and $57 \%$ for those aged under $20,20-64$ and 65 year and over respectively. Today, the NHI covers more than $98 \%$ of Taiwan's 23 million population and enrollees enjoy almost free access to healthcare, except for a small co-payment, plus some registration fees that, although not mandatory, are required by most clinics and hospitals. Yet while this expansion of coverage will almost inevitably have improved access to health care, given evidence of significant disparities in

\footnotetext{
* Correspondence: kennank@aol.com

${ }^{3}$ Division of Health Policy Research and Development, Institute of Population Health Sciences, National Health Research Institutes, 35 Keyan Road, Zhunan, Miaoli County 35053, Taiwan

Full list of author information is available at the end of the article
}

utilization under the former system [1], it cannot be assumed that it will necessarily have improved the health of the population. Indeed, Levy and Meltzer [2] and McWilliams [3] have drawn attention to the many existing limitations of existing research linking expansion of coverage to health improvement. In this paper we take advantage of the opportunity provided by the natural experiment of implementing NHI in Taiwan to examine this issue.

Taiwan's NHI scheme has been described previously $[4,5]$. In brief, it is a universal single-payer social health insurance system, based on a public-contract model, offering comprehensive benefits. The main sources of funds are an income-related premium (payroll taxes), with employees, employers, and government all paying a share of premiums. The share of the premiums paid by the insured, by employers, and by government varies according to employment status. For employees in public or private enterprises, the shares are $30 \%, 60 \%$ and $10 \%$ respectively. The high-income self-employed insured pay 
$100 \%$ of the premium themselves. The government pays $100 \%$ of the premium for military personnel and the lowincome unemployed, and pays $40 \%$ of the premium for the other unemployed. The amount collected by the NHI in respect of each enrollee varies according to his or her number of dependents, although dependents in excess of three are effectively insured for free. These insurance premiums are supplemented by smaller contributions from co-payments, alcohol and tobacco taxes and lottery revenues, and recompense from national environmental pollution funds and automobile insurance. In 2008, total national health expenditure was US\$ 23.9 billion, or $6.4 \%$ of GDP (exchange rate 33 NTD:1USD). Expenditure on the NHI was US\$12.8 billion, or $53.5 \%$ of national health expenditure, which equated to $3.4 \%$ of gross domestic product (GDP) [6], which was lower than in most OECD countries [7].

Previous evaluations of Taiwan's NHI have focused on access and cost containment [8-10], with little research on the impact of its introduction on population health. One study found that the NHI had reduced rural-urban disparities in the incidence of ruptured appendicitis [11]. Another found improved access to care by the elderly but no measurable impact on their self-perceived health [12]. Yet another examined changing life expectancy [13], but it failed to identify an overall association with the introduction of NHI although the gap between the most and least healthy townships did narrow significantly. However, as life expectancy captures the entire range of health determinants [14], more specific analyses are needed.

In this paper we seek to identify any contribution of health care using the concept of amenable mortality, or "mortality amenable to health care", applying methods developed by Nolte and McKee [15]. These capture causes of deaths that should not occur in presence of timely and effective health care [16] and have been used in other evaluations of health system performance [17-19].

We hypothesized that, if the introduction of NHI had an impact on population health, this should be reflected by a discontinuity in the trend in amenable mortality but not in non-amenable mortality. We also hypothesized that the effect of NHI would be less apparent among the working age population, who were more likely to have been insured previously than non-working age groups. With the advantage of comprehensive high quality death registration data covering a population of almost 23 million, our findings may be relevant to other countries that have yet to establish universal health insurance coverage.

\section{Methods}

We used joinpoint regression analysis [20] to identify changes in mortality trends that might be associated with implementation of NHI in Taiwan, distinguishing mortality from causes considered amenable to health care and mortality from all other causes during 1981-2005.

\section{Data}

Mortality data were taken from the Death Registry Database, maintained by the Taiwan Department of Health, with population data from the Household Population Registration System (HPRS) provided by the Ministry of the Interior. These were used to calculate age, sex and cause-specific mortality rates, coded using the ninth revision of the International Classification of Diseases and Deaths (ICD-9).

\section{Amenable mortality}

Causes of death considered amenable to health care are those defined by Nolte and McKee [15,17]. They include causes such as bacterial infections, treatable cancer, diabetes, cardiovascular and cerebrovascular disease, and complications of common surgical procedures for people under age 75 .

We combined causes of deaths to calculate cause-specific amenable mortality rates. We also include ischemic heart disease (IHD) but treat this cause separately as the precise contribution of health care to reductions in deaths from this condition remains unresolved [21,22]. Also, deaths from IHD tend to dominate analyses because of their large numbers. For consistency with other studies, we here present amenable deaths with and without 50\% IHD $[17,19]$.

The number of deaths from causes other than amenable at ages 0-74 was 40,352 in 1981, rising to 55,141 in 2005 while the corresponding figures for amenable causes (excluding IHD) fell, from 21,508 to 16,441, with deaths from IHD rising from 1,643 to 3,338 in the same period.

\section{Measurement and analysis}

To account for changes in population composition, we calculated age-standardized mortality rates (ASMR) using direct standardization to the 2000 WHO world standard population. The ASMR is the sum of the product of mortality rate in the ith age stratum $\left(M_{i}\right)$ in a given year in Taiwan and the proportion of population of standard (WHO) population in the same age stratum in the same year $\left(S t d P_{i}\right)$ as follows: ASMR $=\sum \mathrm{i}=1 \mathrm{n}[\mathrm{Mi} \times \mathrm{S}-$ tdPi] Analyses were undertaken for all ages 0-74 as well as for three age groups, under 20, 20-64, and 65 years and over. Trends in amenable and non-amenable mortality are shown in Figure 1.

\section{Statistical analyses}

We used joinpoint regression analysis originally developed for use in cancer epidemiology, to identify points 


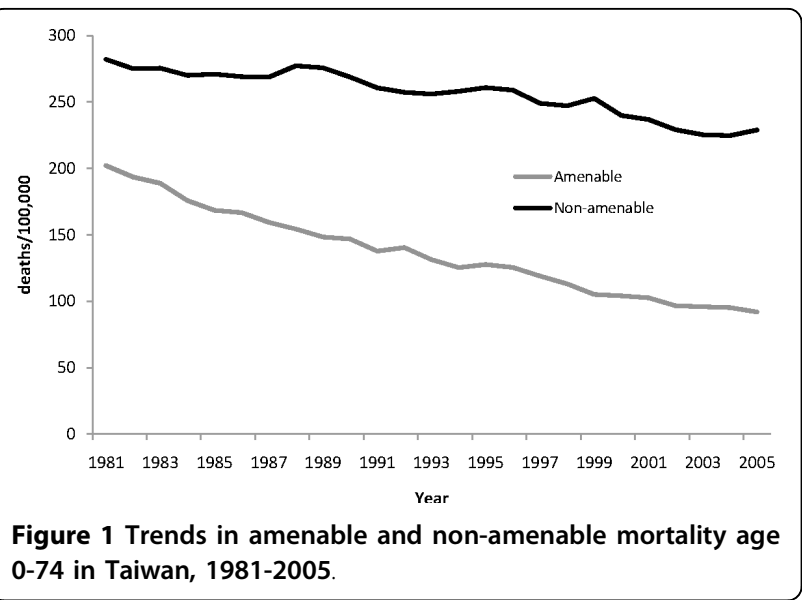

of significant inflection in trends. The analysis starts with minimum number of inflections (joinpoints), and tests whether one or more additional joinpoints should be added to the model. In the final model, each joinpoint indicates a statistically significant change, either increase or decrease, in trend [23]. We selected the Bayesian information criterion approach, which identifies the model with the best fit by penalizing the cost of extra parameters. The annual percentage change (APC) is calculated for the time segments on either side of inflection points. Joinpoint regression analyses were performed using Joinpoint version 3.2 software obtained from the US National Cancer Institute [23].

\section{Results}

Trends in total amenable mortality

Table 1 shows the results of the joinpoint analysis. For all causes of deaths, the decline in the mortality rate was significant before implementation of the NHI. It became briefly insignificant (in both sexes combined and males alone) and again significant immediately after implementation of $\mathrm{NHI}$, at a similar rate of decline to before NHI.

Turning to amenable mortality for men and women combined, the joinpoint analysis identified three significant inflection points, generating four distinct trends between 1981 and 2005. A steady decline from 1981 $(\mathrm{APC}=-4.38, \mathrm{p}<.05)$ was arrested in $1993(\mathrm{APC}=$ -0.53, $\mathrm{p}=.84)$ but then accelerated downward after 1996 (APC $=-5.83, \mathrm{p}<.05)$ before slowing once more in 1999 (APC $=-2.77, \mathrm{p}<.05)$. When analyzed separately, a similar trend was identified for women while for men an additional inflection point was identified in 1987 (APC $=-3.61, \mathrm{p}<.05$ ). Mortality from other causes fell consistently for both sexes between 1981 and 1999 (APC $=-0.64, \mathrm{p}<.05)$, although at a somewhat slower rate compared to amenable mortality; it accelerated downward after 1999 (APC = -2.74, p < .05), arrested in 2003 and thereafter $(\mathrm{APC}=1.04, \mathrm{p}=.65)$. Similar trends were found in men but for women only one inflection point was identified in 1989, following a smaller decline in the previous period.

Table 1 further shows amenable mortality with $50 \%$ of deaths from IHD included. For men and women combined (and also for men alone), the pattern was similar to that seen for amenable mortality without 50\% IHD; but for females, no inflection point was identified. Further analysis using IHD deaths alone for men and women combined reveals that a decelerating increase between 1981 and $1992(\mathrm{APC}=-1.78, \mathrm{p}<0.05)$ was reversed in $1992(\mathrm{APC}=-2.61, \mathrm{p}<.05)$. Similar trends were found in men but for women, an additional inflection point was identified in 1998 ( $\mathrm{APC}=-2.66, \mathrm{p}>.05$ ), following an accelerated downward trend after 1992 $(\mathrm{APC}=-6.73, \mathrm{p}<.05)$.

\section{Trends of amenable mortality by age}

Tables 2 stratifies amenable mortality by age groups for both sexes. It suggests that the effect of NHI implementation was more apparent among those under age 20 . A declining trend in amenable mortality briefly reversed between 1992 or 1993 and 1996, followed by a significant decrease thereafter $(\mathrm{APC}=-5.84)$. For those at working age (20-64 years) there was no significant effect of NHI except for the period 1999-2005. A similar pattern was seen for those aged 65 and over, although the magnitude of the decline in amenable mortality during 1999-2005 (APC $=-2.91, \mathrm{p}<.05)$ was higher than among those of working age $(\mathrm{APC}=-1.21, \mathrm{p}<.05)$.

\section{Trends of amenable mortality by sub-group amenable causes}

Table 3 summarizes the analyses for major amenable causes of death. For circulatory diseases, the picture was similar to that for all amenable causes. On average, the ASMR declined significantly (10.19\%, 8.63\% and 9.13\% per year) among women, men, and both combined respectively, following the introduction of NHI (19961999). These trends continued at a slower, but still significant rate during 1999-2005. The ASMR for treatable cancers increased significantly during 1990-97. Soon after the introduction of NHI, the trends for women $(\mathrm{APC}=-1.49, \mathrm{p}<.05)$ and for both sexes together (APC $=-0.75, \mathrm{p}<.05$ ) began to reverse, significantly so, during 1997-2005. The trend for men continued to increase, although at a slower rate, becoming insignificant during 1997-2005. Trends in infectious diseases showed no clear pattern except for a significant decline after 1997 for men (APC $=-10.03, \mathrm{p}<.05)$. There was no significant change in trends of respiratory disease and genitourinary disease mortality that can be associated with the introduction of NHI. 
Table 1 Joinpoint regression analyses on age-standardized amenable mortality rates in Taiwan, 1981-2005

\begin{tabular}{|c|c|c|c|c|c|c|c|c|c|c|}
\hline \multirow[b]{2}{*}{ Mortality } & \multicolumn{2}{|c|}{ Trend 1} & \multicolumn{2}{|c|}{ Trend 2} & \multicolumn{2}{|c|}{ Trend 3} & \multicolumn{2}{|c|}{ Trend 4} & \multicolumn{2}{|c|}{ Trend 5} \\
\hline & Time Period & APC & Time Period & APC & Time Period & APC & Time Period & APC & Time Period & APC \\
\hline \multicolumn{11}{|l|}{ All causes } \\
\hline Both genders & 1981-1993 & $-1.74^{*}$ & 1993-1996 & -0.57 & 1996-2003 & $-2.50^{*}$ & 2003-2005 & 0.06 & & \\
\hline Females & 1981-1996 & $-2.22^{*}$ & 1996-2005 & $-2.72^{*}$ & & & & & & \\
\hline Males & 1981-1984 & $-2.36^{*}$ & 1984-1993 & $-1.23^{*}$ & 1993-1996 & -0.09 & 1996-2003 & $-2.25^{*}$ & 2003-2005 & 1.08 \\
\hline \multicolumn{11}{|l|}{ Amenable causes } \\
\hline Both genders & 1981-1993 & $-4.38^{*}$ & 1993-1996 & -0.53 & 1996-1999 & $-5.83^{*}$ & 1999-2005 & $-2.77^{*}$ & & \\
\hline Females & 1981-1993 & $-4.45^{*}$ & 1993-1996 & -1.48 & 1996-1999 & $-5.70^{*}$ & 1999-2005 & $-3.21^{*}$ & & \\
\hline Males & 1981-1987 & $-5.05^{*}$ & 1987-1993 & $-3.61^{*}$ & 1993-1996 & -0.53 & 1996-1999 & $-5.77^{*}$ & 1999-2005 & $-2.45^{*}$ \\
\hline \multicolumn{11}{|c|}{ Other causes (non-amenable causes) } \\
\hline Both genders & 1981-1999 & $-0.64^{*}$ & 1999-2003 & $-2.74^{*}$ & 2003-2005 & 1.04 & & & & \\
\hline Females & 1981-1989 & -0.48 & 1989-2005 & $-1.80^{*}$ & & & & & & \\
\hline Males & 1981-1999 & $-0.37^{*}$ & 1999-2003 & $-2.47^{*}$ & 2003-2005 & 1.72 & & & & \\
\hline \multicolumn{11}{|c|}{ Amenable causes with 50\% IHD } \\
\hline Both genders & 1981-1993 & $-4.04^{*}$ & 1993-1996 & -0.81 & 1996-1999 & $-5.67^{*}$ & 1999-2005 & $-2.61^{*}$ & & \\
\hline Females & $1981-2005$ & $-3.86^{*}$ & & & & & & & & \\
\hline Males & 1981-1987 & $-4.66^{*}$ & 1987-1993 & $-3.18^{*}$ & 1993-1996 & -0.78 & 1996-1999 & -5.50 & 1999-2005 & $-2.22^{*}$ \\
\hline \multicolumn{11}{|l|}{$\mathrm{IHD}$} \\
\hline Both genders & 1981-1992 & $1.78^{*}$ & 1992-2005 & $-2.61^{*}$ & & & & & & \\
\hline Females & 1981-1992 & 1.51 & 1992-1998 & -6.73 & 1998-2005 & -2.66 & & & & \\
\hline Males & 1981-1992 & $2.29^{*}$ & 1992-2005 & $-1.63^{*}$ & & & & & & \\
\hline
\end{tabular}

Note. $\mathrm{APC}=$ annual percent change; $\mathrm{IHD}=$ ischemic heart disease.

* APC is statistically significantly different from zero (2-sided at $p<.05)$.

\section{Discussion}

In this study we assessed changes in amenable mortality before and after implementation of universal health insurance coverage in Taiwan. We find that the introduction of NHI was associated with a significant acceleration in the rate of decline of causes of death considered amenable to health care. In contrast, there was no clear change in the trend of mortality from conditions not considered amenable to health care that could be associated with the introduction of NHI. These findings are in general consistent with our hypothesis and with studies reviewed by Levy and Meltzer which, while noting methodological limitations, found that improved health insurance coverage was associated with improved health [2,3,24-27].

Our study also found that the association with the introduction of NHI was more apparent among the young, aged less than 20 years, followed by the elderly, and least among the working age population. This result is consistent with our expectations as $77 \%$ of the working age population were already covered by the preexisting social insurance; thus they were inevitably going to be affected less by the introduction of NHI. In contrast, most children, except children of government employees, were previously uninsured; only $14 \%$ of those aged 20 had social insurance coverage and therefore had more to gain.

Our analysis did not find substantial benefits accruing to elderly people but it must be recalled that amenable deaths occur, by definition, below the age of 75 years. This is for a number of reasons, including the problems of coding often multiple co-existing causes contributing to death, but it does constrain the power of our study to identify a true effect. Furthermore, unlike with children,

Table 2 Joinpoint regression analyses on amenable mortality rates by age-group in Taiwan, 1981-2005

\begin{tabular}{|c|c|c|c|c|c|c|c|c|c|c|}
\hline \multirow[b]{2}{*}{ Age group } & \multicolumn{2}{|c|}{ Trend 1} & \multicolumn{2}{|c|}{ Trend 2} & \multicolumn{2}{|c|}{ Trend 3} & \multicolumn{2}{|c|}{ Trend 4} & \multicolumn{2}{|c|}{ Trend 5} \\
\hline & Time Period & APC & Time Period & APC & Time Period & APC & Time Period & APC & Time Period & APC \\
\hline Under 20 years & 1981-1987 & $-11.64^{*}$ & 1987-1993 & $-3.29 *$ & 1993-1996 & 12.36 & 1996-2005 & $-5.84^{*}$ & & \\
\hline 20-64 years & 1981-1987 & $-4.63^{*}$ & 1987-1996 & $-2.27^{*}$ & & & 1996-1999 & -4.75 & 1999-2005 & $-1.21^{*}$ \\
\hline 65 years and over & 1981-1989 & $-4.06^{*}$ & 1989-1993 & $-6.33^{*}$ & 1993-1996 & -1.31 & 1996-1999 & -5.29 & 1999-2005 & $-2.91^{*}$ \\
\hline
\end{tabular}

Note. $\mathrm{APC}=$ annual percent change.

${ }^{*}$ APC is statistically significantly different from zero (2-sided at $p<.05$ ). 
Table 3 Joinpoint regression analyses on sub-group age-standardized amenable mortality rates in Taiwan, 1981-2005

\begin{tabular}{|c|c|c|c|c|c|c|c|c|c|c|}
\hline \multirow[b]{2}{*}{ Diseases } & \multicolumn{2}{|c|}{ Trend 1} & \multicolumn{2}{|c|}{ Trend 2} & \multicolumn{2}{|c|}{ Trend 3} & \multicolumn{2}{|c|}{ Trend 4} & \multicolumn{2}{|c|}{ Trend 5} \\
\hline & Time Period & APC & Time Period & APC & Time Period & APC & Time Period & APC & Time Period & APC \\
\hline$\overline{\text { Circulatory }^{a}}$ & 1981-1984 & $-3.25^{*}$ & 1984-1993 & $-6.35^{*}$ & 1993-1996 & -3.80 & 1996-1999 & $-9.13^{*}$ & 1999-2005 & $-4.12^{*}$ \\
\hline Females & 1981-1988 & $-5.11^{*}$ & 1988-1993 & $-8.53^{*}$ & 1993-1996 & -5.40 & 1996-1999 & $-10.19^{*}$ & 1999-2005 & $-5.51^{*}$ \\
\hline Males & 1981-1983 & -1.13 & 1983-1993 & $-5.75^{*}$ & 1993-1996 & -1.91 & 1996-1999 & $-8.63^{*}$ & 1999-2005 & $-3.33^{*}$ \\
\hline Infections $^{\mathrm{b}}$ & 1981-1986 & $-9.05^{*}$ & 1986-1989 & 2.62 & 1989-1993 & $-5.47^{*}$ & 1993-2005 & $-9.65^{*}$ & & \\
\hline Females & 1981-1985 & $-8.78^{*}$ & 1985-1992 & -0.99 & $1992-2005$ & $-10.82^{*}$ & & & & \\
\hline Males & 1981-1986 & $-9.37^{*}$ & 1986-1989 & 2.95 & 1989-1997 & $-7.10^{*}$ & 1997-2005 & $-10.03^{*}$ & & \\
\hline Cancer $^{c}$ & 1981-1991 & 0.29 & 1991-1997 & $2.96^{*}$ & 1997-2005 & $-0.75^{*}$ & & & & \\
\hline Females & 1981-1990 & $0.63^{*}$ & 1990-1997 & $2.11^{*}$ & 1997-2005 & $-1.49^{*}$ & & & & \\
\hline Males & 1981-1991 & -0.73 & 1991-1997 & $4.56^{*}$ & $1997-2005$ & 0.77 & & & & \\
\hline Respiratory $^{d}$ & 1981-1984 & $-16.06^{*}$ & 1984-1990 & 4.43 & 1990-1993 & -12.52 & 1993-2005 & -0.09 & & \\
\hline Females & 1981-1984 & $-17.45^{*}$ & 1984-1990 & 2.34 & 1990-1994 & -12.80 & $1994-2005$ & -1.04 & & \\
\hline Males & 1981-1983 & -22.29 & 1983-1990 & 4.13 & 1990-1993 & -10.16 & 1993-2005 & 0.53 & & \\
\hline Genitourinary $^{\mathrm{e}}$ & 1981-1989 & $-5.61^{*}$ & 1989-1995 & 1.96 & 1995-1999 & -4.75 & 1999-2002 & 3.36 & 2002-2005 & -2.83 \\
\hline Females & 1981-1988 & $-5.78^{*}$ & $1988-2005$ & $-1.13^{*}$ & & & & & & \\
\hline Males & 1981-1989 & $-5.47^{*}$ & 1989-1995 & $3.13^{*}$ & 1995-1999 & -4.23 & 1999-2005 & 0.84 & & \\
\hline
\end{tabular}

Note. $\mathrm{APC}=$ annual percent change.

${ }^{a}$ include chronic rheumatic heart disease, hypertensive disease, and cerebrovascular disease

b include intestinal infections, tuberculosis, other infections (diphtheria, tetanus, poliomyelitis), whooping cough, septicemia, and measles

' include colon and rectum, skin, breast, cervix uteri, cervix uteri and body of uterus, testis, Hodgkin's disease, and leukemia

d include all respiratory diseases, influenza, and pneumonia

e include nephritis and nephrosis, and benign prostatic hyperplasia

* APC is statistically significantly different from zero ( 2 -sided at $p<.05$ ).

where coverage was very low, $57 \%$ of elderly people were already covered by social insurance before the introduction of NHI. In addition, elderly people in poor health may have selectively enrolled in either the Indigent Health Insurance or Farmers Health Insurance (FHI) schemes introduced in 1989, or fraudulently used vouchers of people with insurance coverage to visit a doctor, something that was not uncommon in the previous system. Taken together, these factors may explain the weak association between introduction of NHI and health gain among the elderly. However, our finding that the effect attributed to NHI varied among people with different levels of social insurance coverage supports the view that the decline in amenable mortality was related to introduction of NHI.

Our finding of a significant effect of NHI on population health may seem to contradict previous studies in Taiwan that were unable to demonstrate a significant gain in life expectancy a decade after the introduction of NHI [13] or significant changes in perceived health status among the elderly [12]. However, the present study uses a more specific measure of the contribution of health care $[15,17]$ whereas changes in life expectancy and perceived health status are likely to reflect a broader spectrum of health determinants including changes in life style, environmental and biological factors. Furthermore, the application of joinpoint regression in this study allows us to identify inflection points and relate them to the introduction of NHI, something not possible with the earlier studies that simply compared before and after findings.

Our study is also inconsistent with the Rand health insurance study $[28,29]$, a randomized controlled trial which found health insurance coverage, with a few exceptions, did not improve the health of adults. However, as Levy and Meltzer [2] have noted, it did not include people who previously had no health insurance; nor did it include elderly persons so the results are not comparable.

The analysis by major causes of amenable death yields results that are consistent with those found elsewhere [19]. A more detailed analysis (data not shown) revealed that the decline in circulatory diseases was largely due to a reduction in cerebrovascular and hypertensive mortality, which can plausibly be linked to a documented significant improvement in hypertension control [28] as well as, potentially, better quality of care in cerebrovascular disease. The decline in female cancer mortality can be attributed to a reduction in deaths from cervical cancer, associated with increased use of Pap smear screening [30,31], and improved outcomes with leukemia. Our finding of a significant reduction in male infectious disease mortality (-10.03\% during 1997-2005) was due to a substantial decline in mortality from tuberculosis and septicemia in Taiwan during the study period (data not shown). 
It is necessary to discuss what may seem like an inconsistency, whereby the causes of death making the greatest contribution to the overall decline in amenable mortality are rare in young people, who exhibit the greatest falls in amenable deaths. This is because the underlying death rate is low at young age groups, so reductions in amenable mortality from causes dominating here (that are less common at older ages) will have little impact on total amenable mortality. In contrast, a smaller reduction at older ages, where overall death rates are much higher, will allow those causes of death common in this age group to dominate amenable mortality overall.

Our study design, a large-scale (23 million population) national natural experiment using a joinpoint method, while observational in nature, allows us to compare changes in amenable mortality across different periods in time with mortality not considered amenable to health care and among different age groups with different health insurance coverage. However, the design, does not allow us to rule out all alternative explanations, and prevents us drawing causal inference, a problem identified by Levy and Meltzer in all observational studies [2]. Besides, we were not able, in this analysis, to assess the health impact of expansion of insurance coverage at the individual level. The aggregate change, which includes the $60 \%$ who already had coverage before the introduction of NHI, will therefore underestimate the impact on the previously uninsured. An earlier study did, however, find that overall life expectancy, with all its limitations as a measure of health system performance, improved more in the poorest in Taiwanese society after introduction on NHI [13].

It is difficult to explain the levelling out in the decline in amenable mortality in 1993 to 1996. Some tentative explanations can, however, be advanced. First, the rate of expansion of insurance coverage had been slowing between 1987 and 1994. Second, it took some time for the NHI to become established. It was launched in March 1995, three months into the year and unemployed people could delay enrollment for the first year. Third, it took some time for the health care delivery system to respond to the new financing model; for example, adult preventive services were not launched until April 2006. Finally, the NHI paid little attention to access by people living in remote areas until 1996. However, it may simply be that the major organizational changes involved in implementing NHI caused those working in the health care delivery system to be distracted from their core activities. This would be consistent with research on other forms of organizational change, such as hospital mergers, where the process of reorganization can lead to a loss of managerial focus and reduction in quality of care that can last for several years [32,33]. This is, however, a finding that requires further exploration.

Looking ahead, while the Taiwanese NHI has succeeded in terms of cost (3.4\% of GDP), satisfaction (77.5\% satisfied in 2007), low administrative cost (1.49\%), and equitable financial burden [8,9], the system is not without problems. For example, as a publiclymanaged program, it is difficult to insulate it from political interference, a factor that has contributed to a continuing financial deficit. Thus, the existing budget may be inadequate to sustain the current level of performance [34].

\section{Limitations}

Our study also suffers from some limitations. First, reductions in amenable mortality may reflect a combination of three factors. These are improved access to care (for example through expansion of coverage), improved quality, and therapeutic innovation. As we have argued, it is plausible, given the timings of the changes observed, that the first of these has been important but we cannot exclude a contribution from the second and third. The only relevant data we have been able to find relate to case fatality from myocardial infarction, which improved steadily from 1996 onwards [35], but we are unable to ascertain whether this was a deviation of earlier trends. Second, as with most research on the contribution of health care to population health, by omitting potentially important factors that might reduce the underlying incidence of treatable diseases and thus the burden on the health care system. These include improvements in education, nutrition, and exposure to risk factors such as tobacco and alcohol. We were also unable to take account of possible changes in the delivery of health care or the ability to pay for care outside the NHI scheme.

Third, there are likely to be variable lag periods between expansion of coverage and reduction in amenable mortality. For example, the immediate treatment of a myocardial infarction (e.g. thrombolysis) may have an impact at once while treatment with statins or antihypertensives will reduce risk after a longer (and variable) period. The consequences will be to dilute any effect of the introduction of NHI.

Thus, our results must be interpreted with some caution.

\section{Policy Implications}

These findings have implications for other countries that do not have universal health insurance coverage. The implementation of NHI in Taiwan was associated with a sustained reduction in deaths from causes amenable to health care, which surpassed the underlying decline in other causes. It is reasonable to expect that the 
introduction of universal coverage elsewhere might also have beneficial effects [19].

\section{Conclusions}

Our study found that the expansion of health insurance coverage by Taiwan's NHI may have achieved one of its goals, to improve the health of the nation's population. The effect was most apparent among the age groups who were previously least likely to be insured. The major contribution to declining amenable mortality was the reduction in deaths from circulatory diseases, male infectious diseases and female treatable cancers. Our study takes advantage of a large scale natural experiment and uses the joinpoint method, to evaluate the impact of introducing NHI on population health. There are, however, some caveats. The design is not strong enough to rule out all alternative explanations than NHI. Besides, the observed gains are likely to be greater among those previously uninsured and we may have underestimated the scale of improvement because of coincident changes to recording of infant deaths.

\begin{abstract}
Abbreviations
NHI: National Health Insurance; NHE: National Health Expenditure; GDP: gross domestic product; OECD: Organisation for Economic Co-operation and Development; HPRS: Household Population Registration System; ICD9: International Classification of Diseases and Deaths; IHD: ischemic heart disease; ASMR: age-standardized mortality rates; APC: annual percentage change; FHI: Farmers Health Insurance
\end{abstract}

\section{Acknowledgements}

We thank the Department of Health in Taiwan for providing the Death Registry Data. The authors had permission from the Department of Health to use those data for analysis with full access to all of the data in the study. YCL and YTH take full responsibility for the integrity of the data and the accuracy of the data analysis.

\section{Author details}

${ }^{1}$ Institute of Health and Welfare Policy, College of Medicine, National YangMing University, Taipei, Taiwan. ${ }^{2}$ Department of Gerontological Care and Management, Chang Gung Institute of Technology, Tao-Yuan, Taiwan. ${ }^{3}$ Division of Health Policy Research and Development, Institute of Population Health Sciences, National Health Research Institutes, 35 Keyan Road, Zhunan, Miaoli County 35053, Taiwan. ${ }^{4}$ Office of Statistics, Department of Health, Taipei, Taiwan. ${ }^{5}$ European Centre on Health of Societies in Transition, London School of Hygiene and Tropical Medicine, London, UK. ${ }^{6}$ Director Health and Healthcare, RAND Europe, Cambridge, UK.

\section{Authors' contributions}

YCL and KNK conceived the study and participated in study design, analysis and interpretation of data, wrote the article, and study supervision. YTH participated in the design of the study, analysis and interpretation of data, statistical analysis, and drafting the manuscript. SMH contributed to acquisition of data and analysis and interpretation of data. YWT, MM and EN contributed analysis and interpretation of the data and critical revision of the manuscript.

All authors read and approved the final manuscript.

\section{Competing interests}

The authors declare that they have no competing interests.

Received: 5 March 2010 Accepted: 4 August 2010

Published: 4 August 2010
References

1. Cheng SH, Chiang TL: Disparity of medical care utilization among different health insurance schemes in Taiwan. Soc Sci Med 1998, 47:613-620.

2. Levy H, Meltzer D: The impact of health insurance on health. Annu Rev Public Health 2008, 29:399-409.

3. McWilliams JM: Health consequences of uninsurance among adults in the United States: recent evidence and implications. Milbank Q 2009, 87:443-494.

4. Peabody JW, Yu JC, Wang YR, Bickel SR: Health system reform in the Republic of China: formulating policy in a market-based health system. JAMA 1995, 273:777-781.

5. Chiang TL: Taiwan's 1995 health care reform. Health Policy 1997, 39:225-239.

6. Taiwan Department of Health: Health and National Health Insurance Annual Statistics Information Service. [http://www.doh.gov.tw/statistic/ index.htm], Accessed June 1, 2009.

7. Organisation for Economic Co-operation and Development: OECD Health Data 2007. [http://stats.oecd.org/Index.aspx?DataSetCode=HEALTH], Accessed February 4, 2009.

8. Cheng TM: Taiwan's new national health insurance program: genesis and experience so far. Health Aff (Millwood) 2003, 22(3):61-76.

9. Lu JF, Hsiao WC: Does universal health insurance make health care unaffordable? lessons from Taiwan. Health Aff (Millwood) 2003, 22(3):77-88

10. Lee YC, Yang MC, Li CC: Health care financing system in Taiwan: before and after introduction of case-mix. Malaysian J Public Health 2005, 5(Suppl 2):19-32.

11. Huang N, Yip W, Chang HJ, Chou YJ: Trends in rural and urban differentials in incidence rates for ruptured appendicitis under the National Health Insurance in Taiwan. Public Health 2006, 120:1055-1063.

12. Chen L, Yip W, Chang MC, Lin HS, Lee SD, Chiu YL, Lin YH: The effects of Taiwan's National Health Insurance on access and health status of the elderly. Health Econ 2007, 16:223-242.

13. Wen CP, Tsai SP, Chung WS: A 10-year experience with universal health insurance in Taiwan: measuring changes in health and health disparity. Ann Intern Med 2008, 148:258-267.

14. Davis K, Huang AT: Learning from Taiwan: experience with universal health insurance. Ann Intern Med 2008, 148:313-314.

15. Nolte E, McKee M: Does health care save lives? Avoidable mortality revisited. London: Nuffield Trust 2004.

16. Rutstein DD, Berenberg W, Chalmers TC, Child CG, Fishman AP, Perrin EB: Measuring the quality of medical care: a clinical method. $N$ Engl J Med 1976, 294:582-588.

17. Nolte $E$, McKee M: Measuring the health of nations: analysis of mortality amenable to health care. BMJ 2003, 327:1129-1132.

18. Charlton JR, Hartley RM, Silver R, Holland WW: Geographical variation in mortality from conditions amenable to medical intervention in England and Wales. Lancet 1983, 1(8326 Pt 1):691-696.

19. Nolte $E$, McKee CM: Measuring the health of nations: updating an earlier analysis. Health Aff (Millwood) 2008, 27(1):58-71.

20. Kim HJ, Fay MP, Feuer EJ, Midthune DN: Permutation tests for joinpoint regression with applications to cancer rates. Stat Med 2000, 19:335-351.

21. Capewell S, Morrison CE, McMurray JJ: Contribution of modern cardiovascular treatment and risk factor changes to the decline in coronary heart disease mortality in Scotland between 1975 and 1994. Heart 1999, 81:380-386.

22. Ford E, Ajani U, Croft J, Critchley J, Labarthe D, Kottke T, Giles W, Capewell S: Explaining the decrease in U.S. deaths from coronary disease, 1980-2000. N Engl J Med 2007, 356:2388-2398.

23. Joinpoint Regression Program. Version 3.2. Statistical Research and Applications Branch, National Cancer Institute. [program] Statistical Research and Applications Branch, NCIBethesda MD .

24. Currie J, Gruber J: Saving babies: the efficacy and cost of recent changes in the Medicaid eligibility of pregnant women. J Polit Econ 1996, 104:1263-1296.

25. Fox MH, Moore J, Davis R, Heintzelman R: Changes in reported health status and unmet need for children enrolling in the Kansas children's health insurance program. Am J Public Health 2003, 93:579-582.

26. Hadley J, Waidmann T: Health insurance and health at age 65: implications for medical care spending on new Medicare beneficiaries. Health Serv Res 2006, 41:429-451. 
27. Raghavan R, Aarons GA, Roesch SC, Leslie LK: Longitudinal patterns of health insurance coverage among a national sample of children in the child welfare system. Am J Public Health 2008, 98:478-484.

28. Brook RH, Ware JE, Rogers WH, Keeler EB, Davies AR, Donald CA, Goldberg GA, Lohr KN, Masthay PC, Newhouse JP: Does free care improve adults' health? results from a randomized controlled trial. $N$ Engl J Med 1983, 309:1426-1434

29. Keeler EB, Brook RH, Goldberg GA, Kamberg CJ, Newhouse JP: How free care reduced hypertension in the health insurance experiment. JAMA 1985, 254:1926-1931.

30. Chen CJ, You SL, Lin LH, Hsu WL, Yang YW: Cancer epidemiology and control in Taiwan: a brief review. Jpn J Clin Oncol 2002, 32(Suppl 1): S66-S81.

31. Koong SL, Yen AMF, Chen THH: Efficacy and cost-effectiveness of nationwide cervical cancer screening in Taiwan. J Med Screen 2006, 13(Suppl 1):S44-S47.

32. Fulop N, Protopsaltis G, King A, Allen P, Hutchings A, Normand C: Changing organisations: a study of the context and processes of mergers of health care providers in England. Soc Sci Med 2005, 60:119-130.

33. Sari N: Do competition and managed care improve quality? Health Econ 2002, 11:571-584.

34. Reinhardt UE: Humbled in Taiwan. BMJ 2008, 336:72

35. Hsiao WC, Chou YJ, Yip WC, Lu JF, Li YC: Evaluation of Taiwan's National Health Insurance. Research report funded by the Bureau of National Health Insurance (DOH-90-NH-017), The Department of Health, Taipei, Taiwan 2003.

\section{Pre-publication history}

The pre-publication history for this paper can be accessed here: http://www.biomedcentral.com/1472-6963/10/225/prepub

doi:10.1186/1472-6963-10-225

Cite this article as: Lee et al:: The impact of universal National Health Insurance on population health: the experience of Taiwan. BMC Health Services Research 2010 10:225.

\section{Submit your next manuscript to BioMed Central} and take full advantage of:

- Convenient online submission

- Thorough peer review

- No space constraints or color figure charges

- Immediate publication on acceptance

- Inclusion in PubMed, CAS, Scopus and Google Scholar

- Research which is freely available for redistribution 